\title{
Teaching-Research-Innovation Nexus: Towards an Entrepreneurial University of Technology
}

\author{
Prof. A.H. Louw \\ Vaal University of Technology \\ Vanderbijlpark, 1911, South Africa \\ Email: alouw@vut.ac.za \\ Prof. K.C. Moloi \\ Vaal University of Technology \\ Faculty of Human Sciences, Vaal University of Technology \\ Email: conniem@vut.ac.za
}

Doi:10.5901/mjss.2013.v4n13p63

\begin{abstract}
The aim of this article is to present a possible teaching-research-innovation synergy framework that may work for one University of Technology (UoT) that is moving towards becoming an entrepreneurial university in order to bring about practical solutions for the socio-economic needs of the surrounding communities. A literature review was undertaken to interrogate the possibility of applying the teaching-research-innovation nexus at one university of technology in South Africa. Literature shows that the teaching-research-innovation nexus is a debate that has always occupied higher education. Some researchers argue that there can be no teaching without research or research without teaching. However, bringing synergy between teachingresearch and innovation is a complex process. The literature revealed that in order to realise the synergy among the three forces it is vital for an entrepreneurial university to forge partnerships with industry and surrounding communities. The authors believe that, with broad economic participation, innovation and new enterprise development - realisable for instance through a science park within the institution to support entrepreneurship - poverty among neighbouring communities can be mediated. The process will contribute to the country's development initiatives.
\end{abstract}

Keywords: teaching-research-innovation synergy; entrepreneurial university-industry synergy; innovation; teaching-learning improvement; socio-economic development; knowledge society.

\section{Introduction}

During the start of the transition process in South Africa, and with the transformation of higher education (HE), development was identified as a strategy to create equitable opportunities for all South Africans. The transformation of higher education into an open, non-racial and non-sexist system was geared to serving national needs in response to the pressures of macro-economic policies driven by globalisation and information communication technologies (Ten-Year Plan for South Africa 2008-2018:i). These forces, according to Singh, Kenway and Apple (2007:4), characterise modern social life by means of a complex connectivity. Indeed, as indicated in the Reviews of National Policies on Education in South Africa (2008), HE is expected to deliver the required research results, highly trained people with knowledge, competences and attitudes to equip a developing society with the capacity to address national needs and to participate effectively in a rapidly changing and competitive global marketplace. In his 2013 budget speech, the Minister of Finance, Mr Pravin Gordhan, indicated that the first reality we need to contend with is South Africa's demographic transition in which a million young people leaves school every year. A package of reforms improving education, training and work opportunities for young people is needed (p.7). These, according to Gordhan, are some of the themes on which the National Development Plan (NDP) provides clear guidance, not just about strategic goals and objectives, but also about the practical difficulties and choices the country faces.

In view of these expectations the University of Technology (UoT), upon investigation has embarked on moving more towards an entrepreneurial university through, inter alia, building a teaching-research-innovation synergy culture in the postgraduate programmes. These are the master's degree and PhD studies; research and development niches; technology transfer; innovation and commercialisation of institutional intellectual property; knowledge transfer 
partnerships, as well as the establishment of a science park. This UoT is also particularly driven by the need for the South African Government to urgently confront the failure of the national system of innovation (NSI) to commercialise the results of scientific research (Ten-Year Plan for South Africa 2008-2018:8). In this paper, the authors argue for a framework that may work in the context of a UoT to implement a teaching-research-innovation nexus or synergy as a core strategic goal. To achieve this objective, the institution has extended its teaching-research-innovation synergy to international industry in order to enhance the entrepreneurial aspirations, innovation and commercialisation of knowledge and products. The intention is to assist in addressing unemployment issues in the surrounding communities through localisation of impact. We do however agree with Blankley and Booysens (2011:1) that, while innovation is identified as the key driver of economic growth and productivity, the capacity to innovate remains low in most African countries.

\subsection{Research methods}

A literature review was undertaken to interrogate the possibility of applying the teaching-research-innovation nexus at one university of technology in South Africa. Literature shows that the teaching-research-innovation nexus is a debate that has always occupied higher education. Some researchers argue that there can be no teaching without research or research without teaching. However, bringing synergy between teaching-research and innovation is a complex process.

\subsubsection{Analysis Result}

Business, labour, civil society and higher education should find alignment within the development and progressive agenda of the country through mutual participation in developing and implementing it.

\section{Statement of the problem}

The change towards a global system and the parallel development of a knowledge and information economy inevitably creates a new scenario in terms of development options, drivers and strategies in the business world and within institutions of higher learning, nationally and internationally (Nixon 2007:45). Blankley and Booysens (2011:1) however, caution that while knowledge economy indicators (KEIs), as well as the science and technology indicator initiatives, play a crucial role in national policy debates in South Africa, there are gaps between the conceptual and empirical aspects of measuring the knowledge economy. The current economic crisis is a specific example (Gordhan 2013). It is evident that economic growth in itself does not guarantee human well-being, as is evident for example from the period of jobless growth in South Africa, while social development on its own does not provide a sustainable option (Ten-Year Plan for South Africa 2008-2018).

The government is required to address the "innovation chasm", which means improving access to finance, creating an innovation-friendly regulatory environment and strengthening the National System of Innovation (NSI). According to Nixon (2007:46), innovations in the microchip, digitization, and computer networking have enabled the creation of global flows of capital that have given rise to transitions in the globalised information economy. Nixon points out that the information technology (IT) telecommunications industries have become central to economic policy, while multimedia software development has been foregrounded in cultural policy. To this end, he reasons, many nations across the globe have developed policies in relation to information technologies (IT), telecommunications, and new media, mobilising the cliché of blurring boundaries to restructure and de-structure the relationship between policies governing the economy, culture and education.

Adding to this complexity is the changing global context, impacting on national development in terms of market, social, political and cultural aspects amongst others. The challenge of finding a balance between all the dimensions impacting on the development process leads to various approaches from the minimum state to opposite extremes, various solutions from basic needs, modernisation and a host of other theories and approaches which we do not discuss here. Despite the acceptance of the critical role that the developmental state plays, the notable case against it in Africa is not faith in flawless markets but rather that whatever the degree and extent of "market failure" the states cannot correct them in ways that do not make things worse (Mkandawire 1998). The argument is that what worked in other "late industrialisers" is not practicable in Africa, for instance a replication of what happened in Asia. The reasons include dependence, lack of ideology, "softness", lack of technical and analytical capacity, a changed international environment that does not permit protection of industrial policies, and a past poor record of performance. 
In our schema, these arguments create space for all types of interventions, and often exploitation, in Africa. In this context, Mills (2010:1) argues that Africa is required to embrace a far greater degree of political and economic freedom. We argue that the position should be to integrate in the developmental agenda provision to capitalise on opportunity, but at the same time make arrangements to accommodate the capacity requirements of the developmental state. Continuous rejection of the potential of Africa to develop on this basis is inevitably informed by the perpetuation of skewed perspectives of the real potential. Considering these complex development issues as a UoT we make the case for a movement towards an entrepreneurial university that co-operates with its industry for economic growth and social development in the neighbouring communities. The case for such a movement fundamentally rests, in our schema, on the concept of an entrepreneurial university which pursues the objective of social and economic development as well as sustainability in a number of ways that include centres of excellence for outreach initiatives.

In view of the problems stated here, the research questions are:

- How can institutional change be achieved through the teaching-research-innovation synergy?

- What mechanisms are required to enhance the teaching research-research-innovation synergy?

- How can university-industry synergy enhance economic and social development?

\section{Conceptual issues}

\subsection{Teaching-research-innovation synergy}

To fulfil the purpose of a UoT in the context of a national innovation system, teaching, research and innovation activities should result in practical solutions to address society's needs. Our view is that this mandate can be achieved through using teaching and research as tools for innovation to achieve a higher goal, which is that of making a difference in the community. The Ten-Year Plan for South Africa 2008-2018 states that innovation is the key to scientific and technological progress. This is the government's broad mandate and the grand challenges of science and technology are in accordance with the needs of South African society. For Rensburg (2012:1) innovation is the primary driver of technological growth and living standards. This underscores the constant demand for innovative ways of knowledge creation and sharing between a university and its industry partners. According to Talaba (2007:1), the teaching, research and innovation synergy becomes an interaction of three component agents or forces whose combined effect is greater than the sum of their individual effects. This synergy works together at three levels: (i) teaching and research within the university; (ii) entrepreneurial university and industry synergy; and (iii) bringing about solutions to real problems in society. Talaba (2007:2) points out that very few studies have systematically analysed the synergy between teaching, research and innovation and that there is almost no framework in universities to explicitly stimulate synergy among these three forces. It was this paucity in research studies that led the researchers to undertake this study, and gain understanding of how best institutional change through a teaching-research-innovation synergy can be achieved to assist in reducing unemployment and reduce poverty among the surrounding communities.

\subsection{Development}

The authors argue that development is a multi-faceted concept and its interpretation in practice remains a challenging phenomenon due to the complexity of the operating environments of universities, industry and societies. Although many efforts towards development have been made, the question remains as to what approach could be considered as the solution to improve the well-being of all people. Key to this debate remains the role of the state in the development process and how UoTs can help address economic and social problems in South Africa. A worrying question persists: What is a development state and what is development in the context of an entrepreneurial university? The history of development in Africa has led to disillusionment and the question around the real capacity and role the state should exercise in the development process. The growing trend of disillusionment with purely new-liberal tendencies inevitably impelled South Africa towards a developmental approach to reducing poverty and inequality. This, according to Ramieri and Ramos (2013:1), is inclusive growth in a developmental state.

A democratic developmental approach combines the components of a broad-based national development vision, the systematic deployment of state resources and capacities in a beneficial partnership with democratic society and its institutions of higher learning. The Accelerated Shared Growth Initiative for SA (ASGISA), followed by GEAR, and now the "new growth path" are typical examples of the alternative role to enhance development by means of pro-active state interventions in partnership with the democratic society and, in particular, with universities in the South African context. It 
seems, therefore that there is a dynamic relationship between the ideal role of the state and the level of development of a country as well as the effects on development of the society and the country's economy at the level of university partnerships. The government has consistently emphasised that sustained economic growth is a necessary precondition for South Africa's continued transformation (Reviews on National Policies of Education 2008:25).

\subsection{Entrepreneurial university}

Gibb and Hannon (2007:13) define an entrepreneurial university as one that is unafraid to maximise the potential for commercialisation of its ideas and to create value in society while not seeing this as a significant threat to academic values. In such a university, engagement with stakeholders is actively pursued through a variety of means, including consultancy, research and development, technology transfer, related engagement with and/or ownership of science parks and incubators, as well as pursuit of staff and student project work. Gibb and Hannon indicate that this also means that there is an accepted responsibility for local development, a view of an entrepreneurial university that aligns with the teaching-research-innovation synergy that the UoT is pursuing as a core strategy.

\subsection{Entrepreneurial university-industry synergy}

The drive for international competitiveness and the lead that the higher sector institutions in South Africa seem to be expected to take in shaping institutional development and culture change (Gibb \& Hannon 2007:2) has been the basis, among others, for the synergy between entrepreneurial universities and their surrounding industries for good practice examples. Gibb and Hannon indicate that the complex environment of university-industry co-operation needs to be examined at the parameters that make, for that matter, also synergistic effects and synergy processes in this complex environment. In the context of the UoT under investigation, numerous partnerships and co-operative ventures with surrounding industry, such as, the French Alliance and the National e-Skills (2011), are in place. The effects of this cooperation are visible in the improvement of teaching and learning within the institution and financial effects for both the institution and industry impact on the surrounding communities.

\section{Framework for teaching-research-innovation synergy}

Talaba (2008:2) poses the question: Why is teaching in higher education traditionally accompanied by research? We believe, like most other researchers that the answer lies in the ambit of continuous knowledge creation, diffusion and dissemination, creativity and innovation, responses to new challenges in a knowledge society and knowledge economy. This involves movement from obsolete knowledge processes and procedures. To this end, Talaba (2007) proffers that knowledge is the product around which university business is organised, and research is the production process of knowledge while teaching and learning is the marketing of knowledge (p.3). Thus, the purpose of the Ten-Year Innovation Plan for South Africa is to help drive the country's transformation towards a knowledge-based economy, in which the production and dissemination of knowledge leads to economic benefits and enriches all fields of human endeavour (Ten-Year Plan for South Africa 2008-2018:iii). The Ten-Year Plan proceeds from government's broad socioeconomic mandate, particularly the need to accelerate and sustain economic growth, and is built on the foundation of the NSI. It recognises that, while the country's science and technology system has made significant progress, there is a wide gap between South Africa and those countries identified as knowledge-driven economies.

To close this gap, the NSI must become more focused on long-range objectives, including urgently confronting South Africa's failure to commercialise the results of scientific research, and the country's inadequate production (in both a qualitative and quantitative sense) of knowledge workers capable of building a globally competitive economy. According to this plan, progress towards a knowledge-based economy will be driven by four elements:

- Human capital development;

- Knowledge generation and exploitation (R\&D);

- Knowledge infrastructure; and

- Enablers to address the "innovation chasm" between research results and socio-economic outcomes (TenYear Plan for South Africa 2008-2018:iv).

For a UoT, the teaching-research-innovation synergy becomes an imperative in terms of research added value to teaching, or the teaching added value to research, as tools to provide valid solutions to society's actual problems. Talaba (2007:2) points out that the synergy between an entrepreneurial university and industry takes place between a common, 
but complex, environment. In such an environment, teaching, research and innovation are related to knowledge. The function of research is to generate new knowledge, and that of teaching to prepare and disseminate knowledge, both existing and new. Innovation provides solutions to economic and social problems. The questions to be asked, as suggested by Talaba (2007) in building a teaching-research-innovation synergy, are: What is supposed to be taught in higher education? Who is the most qualified to do it? Where is the most appropriate place for it? When and how will it lead to the teaching-research-innovation synergy? Who will benefit and how? These questions stimulate multidisciplinary thinking and challenge the country's researchers to answer existing questions, create new disciplines and develop new technologies (Ten-Year Plan for South Africa 2008-2018:6). Talaba (2007:5) points to the nature of scholarship in relation to the advancement, synthesis and application of knowledge. In relation to the UoT we premise our move towards becoming an entrepreneurial university to the extent to which visibility of staff research activity is transferred to students. Also the extent to which student learning mirrors research, particularly at postgraduate level, and how this in turn reaches the surrounding communities. The challenge, however, within this UoT is the extent to which a rich research environment exists to enable a strong research culture within the institution that links to classroom teaching and innovation. As with all change processes, we are cognisant that such fundamental change takes time. Nevertheless, we determinedly believe the teaching-research-innovation synergy will ultimately yield results that will optimise the institution's impact on the surrounding communities.

\section{Entrepreneurial university-industry synergy and development}

The Ten-Year Plan for South Africa 2008-2018 indicates that, while the grand challenges for South Africa are structured within a national context, international collaboration and partnerships will be essential to success. Characteristic of the developmental state is, therefore, the underlying logic of bureaucratic autonomy with an unusual degree of public-private co-operation. Consequently, it is evident that there is not necessarily a prototype of developmental states, but rather a variety of characteristics around the central idea of a state with a primary development focus. Based on the discussion it is thus possible to make a brief summative statement on the role of the key stakeholders in the developmental state, as laid out in the grand challenge areas of the Ten-Year Plan for South Africa, 2008-2018:

- The Farmer to Pharma Valu chain to strengthen the bio-economy;

- Space science and technology;

- Energy security;

- Global-change science with a focus on climate change; and

- Human and social dynamics.

Progress in all these areas will be based on the three foundations: technology development and innovation, human capital and knowledge infrastructure (including the research institutions mandated to promote sector research).

In view of the above, the state defines a national developmental focus and creates capacity for decision-making, autonomy (independence from elite control, intervention, planning, decisive action, and functioning as an integrated entity on the basis of a cohesive structure and collective goals that are an inter-agency alignment) and flexibility to create an enabling environment. For example, Zuma (2009:1) states that a more inclusive economy, creating decent work, reducing inequality and defeating poverty can only happen through a new growth path founded on restructuring of the South African economy to improve performance in terms of labour absorption as well as composition and rate of growth. In line with this view, Gordhan (2013:7) believes that there are substantial strengths on which to build and these include a well-established legal system, secure property rights, an effective tax system, world-class higher education institutions and science councils, established energy, transport, water and communications infrastructure networks, expertise and capacity in many areas, mining, construction, retail, finance, logistics and manufactured exports - and a sound macroeconomic and fiscal framework.

Accepting a central role in driving development and redress, the state inevitably places pressure on itself in terms of:

- Its innovative capacity: the ability to be effective and efficient in the development of infrastructure, collection of taxes and delivery of services. It must therefore be flexible and knowledge-orientated. Innovation through the state must also permeate all levels of the economy and society to prevent dysfunctional local economies and government.

- Its co-ordinating role: it must be able to co-ordinate a wide array of policy parameters to promote development, for example, across monitoring, industrial, labour, market policies and the role of UoTs as centres of knowledge creation, diffusion, commercialisation and dissemination. 
- Its role in facilitating the acquisition of private capital growth. Development requires capital.

- Its role in mobilising and engaging democratic society: the success of sustainable development rests on the synergy towards collaborative development.

Indeed, as alluded to in the Ten-Year Plan for South Africa, 2008-2018, a growing percentage of wealth in the world's largest economies is created by knowledge-based industries that rely heavily on human capital and technological innovation. Today's explosive growth in innovation, new products and services can be ascribed to earlier investments in developing knowledge in areas such as, chemistry, biology, earth sciences and nuclear sciences, coupled with phenomenal advances in information technology (pp.2-4). Ultimately, such investment will contribute to more rapid economic and social transformation. By committing to growing the base of scientists and engineers, both in general and in areas offering the most economic potential over the long-term, South Africa is investing in human capital that will serve its needs well into the future.

Gordhan (2013:8) indicates that, by targeting development and new global industries, South Africa can reduce its dependence on imported technology, and become more self-sufficient in such basic commodities as energy and food. He went on to say that the 2013 budget takes the NDP as its point of departure, recognising that the country's medium-term plans are framed in the context of a long-term vision and strategy which focuses on strengthening growth and employment creation. The 2013 budget, according to Gordhan, prioritises improvements in education and expansion of training opportunities. It further promotes progress towards a more equal society and an inclusive growth path (p.8).The involvement of the UOT under investigation is necessary because it has strong faculty programmes in the fields of engineering, biosciences, hospitality and tourism as well as other areas of community engagement programmes. These have had impact on the surrounding communities' lives and needs.

The debates internationally, regionally and nationally have focused on two longstanding and contrasting views of development, namely liberalism (individual property rights, open markets, rule of law and free trade) and mercantilism (economic nationalism, industrial subsidies and high tariffs) (Mills 2010) and, in the context of universities, how these institutions can better serve the macro-economic policies of a globalised and globalising world and respond to the social needs of communities around them. These debates are reinforced by the dominance of globalisation, internationalisation and localisation discourses driven by information and communication technologies (ICTs) which operate on behalf of both institutional politics and the business sector (Nixon 2007:52).Universities in South Africa have encountered much red tape from the state, particularly since the African National Congress (ANC) Government (1994) took over leadership and governance and embarked on the transformation agenda for higher education. With its legacy of inequality and discrimination embedded in the apartheid regime, the challenge has been to build a new national structure based on the principles of universal human rights that would promote justice, equity and non-discrimination in all aspects, including race, colour, language, gender, disability and age (Van Deventer 2012:6). The belief is that the education system forms a crucial conduit through which the ideals, values, knowledge, attitudes, skills and relationships cherished by a society are made available to learners of all ages (Reviews of National Policies for Education 2008:126). For Gordhan (2013:8) this belief reinforces the education accountability chain, with lines of responsibility from state to classroom.

It is for these reasons that the UNT under investigation has embarked on an ambitious undertaking to move towards an entrepreneurial university. This move is against the backdrop of a massive turnaround of this institution from being a Technikon and, for the last six years, having to move towards becoming a University of Technology. While it was generally accepted that academics and staff members in the Technikon sector could be appointed with a minimum of a first degree and some industrial experience, the expectation has shifted significantly since the institution assumed the status of a UoT. Added to this new demand for higher qualifications and appropriate experience for academics and staff, is the institution's mission to be a key player and major catalyst for the development of innovative and technologicallyadvanced people who may contribute meaningfully to the national economy as well as to sustainable development in the neighbouring communities. We believe that this mission can be realised through a teaching-research-innovation synergy that will bring about practical solutions to industry and the surrounding communities (Academic and Staff Development Policy VUT). Indeed, the UoT's mission is in line with the NDP's emphasis on uniting South Africans around a common vision, which is a social compact to reduce poverty and inequality, and raise employment and investment, recognising that progress towards a more equal society requires shared efforts across the public and private sectors as stated by Gordhan (2013:8).

Despite the challenges faced in terms of insufficient material resources, insufficiently qualified staff members (in some areas), a growing student population and pursuance of becoming a credible university, initiatives are being undertaken to lead in quality technology education at the institution and to contribute to the social and economic development in neighbouring communities. Examples of these initiatives are through establishing centres of excellence in 
the institution as well as forging partnerships with industry. These centres of excellence include a science park, institute of sustainable livelihoods (ISL), a mathematics centre, a language development centre, the Tshepiso centre for entrepreneurial excellence (TCEE), a centre for enterprise development (CED), the Iscor Innovation Centre (IIC), a skills hub and a centre for renewable energy (CRE) (Annual Review 2009).

With the understanding that universities are loosely coupled systems which continually import and export energy in order to change, develop and be relevant to contextual needs, we believe that it is essential to create knowledge in order to optimise our impact through focusing efforts at a grassroots level. We are confident that through the teachingresearch-innovation we can help build our neighbouring communities by providing practical solutions to address their socio-economic needs and thereby become part of the solution to address the country's pressing economic and social problems. According to Blankley and Booysens (2011:1), policies to enhance the knowledge economy should include economic development strategies built around innovation, education and learning, as well as policies to develop competitive structures and strong organisations able to deal with global competition and market forces.

In her speech, during the launch of the 2012 National Science week, Naledi Pandor (previous Minister of Technology in South Africa), said: "It is no doubt that science and technology have changed the world tremendously and countries that excel in the sector become powerful players in the economy of the world (p.1)." In addition, Professor Ihron Rensburg (Vice-Chancellor, University of Johannesburg) who attended the launch, indicated that science is an enabler of economic development and that the two (science and economy) are differentiators between countries that were able to tackle poverty effectively by growing and developing the economy and those that were not (p.1). It is therefore clear that the government's broad developmental mandate can ultimately be achieved only if South Africa takes further steps on the road to becoming a knowledge-based economy, in which science and technology, information, and learning move to the centre of economic activity (HSRC Reviews 2011:1) Gordhan (2013:4) however, argues that high levels of debt are inhibiting progress in many countries including South Africa, and that measures to reduce indebtedness have the effect of holding back growth. He continues to say that unemployment remains high in many countries, yet technological progress continues to reduce demand for labour in many industries and subsequently, around the world, inequality is fuelling discontent.

For Rensburg (2012:1), the extent to which developing economies emerge as economic powerhouses depends on their ability to grasp and apply insights from science and technology and use them creatively. The Ten-Year Plan for South Africa, 2008-2018, states that prospects for improved competitiveness and economic growth rely, to a great degree, on science and technology.

The knowledge-based economy rests on four interconnected, interdependent pillars:

- Innovation

- Economic and institutional infrastructure

- Information infrastructure

- Education (pp.2-3).

On these pillars the country is able to attract international investment and to link it to local and global technology, as well as business networks, in ways that promote development. This ability is based on multiple professional-led networks of innovation and international capital, and by the state's flexible organisational structure that enables the effective management of this multiplicity (O'Rian 2000:157-158).

\section{Implications for students success}

For us, education and student success is a contested terrain of survival, struggle, multiple meanings and an agenda of who has the power and what that power does to those who are subjugated by it. Indeed, as Altbach (2002:6) argues, education is not only a commodity to be bought and sold, but also an essential process which underpins civil society and national participation. Through creating enabling learning contexts for teaching-research-innovation we provide epistemological and pedagogical spaces as well as generative learning experiences for our students to use in taking responsibility, making good judgments and striving to contribute towards a better civic society. This enables us, the authors to fuse scholarly rigour with social relevance (Giroux 2006), bring forward the tradition of using pedagogies for knowledge production, future professional work and the possibilities for producing critical, creative students. Despite Western influence on university teaching and learning that is construed as neo-colonialism and a new form of cultural imperialism (Thomas 2005:7), our main mandate as teachers should be to promote the holistic development of the student in preparation for the world of work and responsible citizenship.

For us, the nature of learning is socially situated and it is a process that is co-created through their lived 
experiences, their thoughts and ideas, their voices, feelings, perceptions, their values and culture, and how they construct their own social and intellectual identities as future leaders and professionals in economic, civil and political spheres. From our vantage point, as teachers at a UoT we take cognizance of the tacit knowledge and experiences that constitute the students' individual and collective voices, which they utilise to interrogate the teaching and learning texts that we make available to them. The challenge is for us and our colleagues to re-think teaching as a profession by connecting it to the broader global/national socio-economic conditions, cultural, ideological, intellectual and political contestations that form the contexts within which we educate. Moreover, we are challenged to expand the intellectual world by rethinking a task of knowledge integration that includes the aesthetics, normative and, spiritual developments, the politics of knowledge, gender, serious study of democracy and indigenous knowledge systems and the effects these will have and are having on the ways we look at the future of the curriculum and pedagogy in higher education (Thomas 2005:30). In doing So, we appropriate what Bannett (2000) refers to as an emerging curriculum which emphasises 'knowing how' and 'knowing what'.

The focus of our synergy between teaching, research and innovation therefore becomes the study of knowledge about teacher effects as social practice "within a [politico-] historical framework" (Foucault, 1980: 117). In our conceptual schema we see the nexus as "ruptures or breaks in the systems of reasoning that generate the principles of action and participation", and "ruptures or breaks in the systems of engagement, imagination and alignment in teaching and learning" (Wenger \& McDermont, 2002: 174). Our purpose for educating the young should be to move towards teaching repertoires that are focused on a more politico-pedagogical engagement that lies within the purview of a hermeneutic discourse in which knowledge is always mediated through pre-understanding of our students' socio-cultural contexts. This is about a transformative project that both focuses on the relation of power and knowledge, and that historicises the problem of knowledge. Such a critical approach improves the engagement with learning material, learning activities, modes of content delivery, and methods and principles of assessment, in combination with the students' social world. Entrenched is a critical pedagogy as a study of social exchange in our classrooms.

In a globalized and globalizing knowledge-economy we are challenged to transform our teaching and learning repertoires by providing epistemological access to address the academic needs of our students and to be responsive to societal interests in terms of knowledge, technology innovation and human resources. This enables us to widen both the appeal and relevance of higher education in a changing, techno-capitalist, colonizing world (Ritzer, 2008:294). We agree with Apple (2004: vii), who contends that educational institutions provide one of the major mechanisms through which power is maintained and challenged. However, our teaching-research-innovation nexus foregrounds scholarly teaching as an analytical process; a visionary process; a mental process; an emergent process; a process of negotiation; a collective process; a reactive process; and a process of reflective engagement (Mintzberg, Ahlstrand and Lampel, 1998). Such an approach to teaching requires that each teacher develops a deep understanding of disciplinary and pedagogical content knowledge and an unceasing process of inquiry into new pedagogies of delivery. Critical here is how we objectify knowledge in terms of our own epistemological and ontological positions as teachers facilitating student learning.

This is an argument for democratic deliberation in teacher development, in which members of various constituent groups have genuine input into the educational process (Zeichner 2009). An engagement of this nature allows space for inter-disciplinarity, in which teachers with diverse epistemological orientations are able to create and share knowledge, learn from each other and then transfer this knowledge to their students. Our quest is to extend intellectual conversations by constructing appropriate contexts to tap critical, civic skills so that our students are able to critically examine their transformative roles in society as engaged citizens.

Such a thesis would argue for a dynamic reflexivity that provides pedagogical spaces for our students' investigations, analyses and cultural responsive communications, premised on the view that they can learn to be producers of useful knowledge. Teaching in this way enables us to use students' cultural wealth or cultural capital and social life to develop a knowledge production pedagogy that embraces a socio-cultural community connectionist theory of learning (Zeichner 2009: xvi). This calls for formidable alertness towards the critical shifts in pedagogies of knowledge production, and the scope for and constitution of practical educational innovations that are shaping the education of the rising generation of global and local cosmopolitan students (Thomas 2005:8). We are challenged to re-write the possibilities for new meta-narratives and identities in our teaching and learning activities.

In our quest for progressive education we need to argue for a critical pedagogy that de-centres the teacher and recentres the student as the subject of the educational practice. In doing so, we will recognise, engage and critique in a way that will transform any undemocratic social practices and institutional structures that produce and sustain inequalities and oppressive social identities and relations within our classrooms. Indeed, when teachers and students learn how to think and learn they advance, influence and become catalysts of equity, social progress and emancipation. They are 
empowered to change from passive consumers to active contributors of knowledge through an analytical discourse practice that engenders the development of cultural and educational spaces that are inclusive, transformative and emancipatory (Giroux, 2006: 234). In line with Thomas's (2005:33) assertion, we should not lose sight of the fact that teaching in higher education is not only about developing knowledge and skills, but that human qualities and dispositions are also important in the process, for these are also part of preparing students for the age of supra-complexity. This allows us to connect critical awareness (transformation of consciousness) and social action (engagement) to the process that each teacher would pursue to ensure that all students are educated.

\section{Conclusion}

The current developmental situation in South Africa is indicative of the widest global socio-economic inequality (HDI Report, 2010). A democratic developmental state is legitimised on the basis of its capacity to concurrently foster productive economic activities and economic growth, and qualitatively improve the living conditions of its people and reduce poverty. Higher education, in particular an entrepreneurial university, becomes a significant partner in achieving this goal. It is evident that failure to achieve this fundamentally confronts the credibility of the national system. It presents a significant risk to national safety and stability if the direction that was chosen fails to deliver on the national needs and aspirations of the people of South Africa. It is critical that the state ensures that it develops its autonomy and capacity to be able to plan and execute its role visibly and effectively.

The establishment of the National Planning Commission is an essential step in clarifying the direction, goals and roles in this process of developing a democratic developmental state. The lack of clear direction and inability to deliver effectively is currently South Africa's greatest challenge en-route to becoming a democratic developmental state. It is evident that the current socio-economic conditions in the country necessitate a welfare component in the development process. Without alleviating poverty it is impossible to create stability and space to establish development processes which progressively engage people in mainstream development. For that reason it is crucial to embark on a conscious process of growing the democratic developmental state, while the welfare state component is managed and progressively reduced whilst actively solving poverty and inequality through effective development activities that can also be entrenched in the UoTs. This reality needs to be managed efficiently to find a continuous balance. The risk is that the ever-growing levels of welfare inevitably compromise the capacity to invest in growth to a level that removes the causes for welfare.

This implies active engagement of business, civil society, labour and higher education to ensure that they fulfil an active role in the process of development and progress. Failure to do this inevitably leads to the state filling the gaps left by inability of these role players, leading to a perpetuation of the welfare state's role. The baseline is that developmental states are in the strongest position to take an economy beyond the narrow logic of private investment. Developmental states achieve goals in the contemporary era not by taking on the tasks of development themselves, but by shaping the capabilities of society and the market to do so (O'Rian, 2000). The key issue to consider here is that institutions are key determinants of social welfare and economic development, and consequently become key targets of reformist pressures (Beeson 2002, 38).

\section{References}

Academic and staff development policy. (2012). Vaal University of Technology. Vanderbijlpark. South Africa.

Altbach, P. (2002). Knowledge and Education as International Commodities: The collapse of the common good. International Higher Education, 27, 6-8.

Apple, M. (2004). 'Ideology and curriculum.' (3rd ed.). London: Routledge Falmer.

Barnett, R. (2000). 'Realizing the University in an age of supercomplexity.' Milton Keynes: Society for Research into Higher Education \& Open University Press.

Beeson, M. (ed.). (2002). Reconfiguring East Asia. Regional institutions and organisations after the crisis. New York: Routledge.

Blankley, W. \& Booysens, I. (2010). Science, technology and innovation indicators. South African journal of Science, 106, 15-20.

Castells M. (1992). "Four Asian Tigers with a Dragon Head: A Comparative Analysis of State, Economy and Society in the Asian Pacific Rim." In: R. Appelbaum \& J. Henderson (Eds.), State and Development in the Asian Pacific (pp.30-42). Newbury Park: Sage Publications.

Chibber, V. (1999). Building a Developmental State: The Korean Case Reconsidered. USA: Sage Publications, Inc., pp. $309-346$.

Chibber, V. (2002). Bureaucratic Rationality and the Developmental State. USA: The University of Chicago Press.

Edigheji, O. (2005). A Democratic Developmental State in Africa. SA: Centre of Policy Studies.

Foucault, M. (1980). Power/Knowledge, Selected Interviews \& Other Writings, 1972-1977. C. Gordon (Ed. And Trans.), New York: 
Herder \& Herder.

Freire, F. (1970). 'Pedagogy of the Oppressed'. New York: Herder \& Herder.

Friedman, S. (2011). New Growth Path Success Needs New Policies. SA: Business Day.

Gibb, A. \& Hannon, P. (2007). Towards the Entrepreneurial University. UK: Durham and Birmingham.

Giroux, HA. (2006). 'The Giroux Reader'. Robbins, Boulder: Colorado: Paradigm.

Gordhan, P. (2013). Budget speech. Parliament, South Africa. March 2013.

Human Development Information Report (2010). Available from: http://hdr.undp.org/en/. Accessed: 3/28/2013.

Huff, W.G. (1995). The Developmental State, Government and Singapore's Economic Development since 1960. Great Britain: Elsevier Science Ltd., 23(8): 1421-1438.

Innovation towards a knowledge-based economy. Ten-Year Plan for South Africa (2008 - 2018). Department of Science and Technology. South Africa: Pretoria.

HSRC Review. (2011). Building a knowledge economy in South Africa. 9, 1-57.

Johnson, C. (1999). The Developmental State: Odyssey of a Concept. CA: Cornell University Press.

Kim, EM. (1993). Contradictions and limits of a developmental state: With illustrations from the South Korean Case. Social Problems. USA: University of California Press on behalf of the Society for the Study of Social Problems, 40, 228-249.

Mills, G. (2010).Why Africa is poor and what Africans can do about it. Cato Institute: The Penguin Group.

Mintzberg, H.; Ahlstrand, B. \& Lampel, J. (1998). Strategy safari: A guided tour through the wilds of strategic management. New York: Free Press.

Mkandawire, T. (1998). Thinking about Developmental States in Africa. Issue 9 of African development in a comparative perspective study. Project sponsored by the Government of Japan.

Nixon, H. (2007). Cultural pedagogies of technology in a globalized economy. In M. Singh; J. Kenway \& M. Apple (Eds.), Globalizing Education: Policies, pedagogies \& politics (pp.45-60). New York: Peter Lang.

Őniş, Z. (1991). Comparative Politics. The Logic of the Developmental State. New York: PhD Program in Political Science of the City University of New York.

Ó Rian, S. (2000). Politics \& Society. The Flexible Developmental State: Globalisation, Information Technology, and the "Celtic Tiger". USA: Sage Publications.

Pandor, N. (2012). SA "becoming a knowledge economy." Science and Technology. SouthAfrica.info. SANews.gov.za.

Ramieri, R. \& Ramos, A. (2013). After All, What is inclusive Growth? International Policy. Centre for inclusive growth. UNDP. One pager, pp. 188.

Rensburg, I. (2012). SA "becoming a knowledge economy." Science and Technology. SouthAfrica.info. SANews.gov.za.

Reviews of National Policies on Education in South Africa. (2008). Directorate for Education's Global Relations Strategy. OECD.

Ritzer, G. (2008). 'Sociological Theory.' (7th ed.) Boston: McGraw-Hill International Edition.

Singh, M; Kenway, J \& Apple, M. (2007). Globalizing education: Perspectives from above and below. In Globalizing Education. Policies, pedagogies \& politics, eds. M. Singh; J. Kenway and M. Apple. New York: Peter Lang.

Talaba, D. (2007). Teaching-Research Synergy and University-Industry cooperation in the knowledge based society. In: European University- Industry Network. Teaching and Research Synergy in the context of University-Industry Cooperation. BrasovEindhoven.

Thomas, E. (2005). 'Knowledge cultures and Higher Education: Achieving balance in the context of globalisation.' Institute of Education, University of London.

Vaal University of Technology. (2009). Annual Review. Vanderbijlpark.

Van Deventer, I. (2012). Management strategies for effective social justice practice in schools. Unpublished PhD Thesis. Potchefstroom: North West University.

Weiler N.H. (1996). 'Knowledge, Politics, and the future of Higher Education: Elements of a worldwide Transformation.' In: R. Hayloe, (Ed.), Knowledge Across Cultures (pp.44-60). Ottawa: OISE Press.

Wenger, E. (1998). Communities of practice: Learning, meaning and identity. New York: Cambridge University Press.

Zeichner, K. (2009). 'Teacher education and the struggle for social justice.' New York: Routledge, 2009.

Zuma, J. (2011). The new growth path: The framework. [Online] Available at: http://webcache.googleusercontent.com/ search?q=cache:b3-21PPRt8sJ:www.info.gov.za. (24 February 2013). 